This is the accepted version of the following article:

Rodríguez-Laguna M.D.R., Gómez-Romero P., Sotomayor Torres C.M., Lu M.-C., Chávez-Ángel E.. Development of low-melting point molten salts and detection of solid-to-liquid transitions by alternative techniques to DSC. Solar Energy Materials and Solar Cells, (2019). 202. 110107: - . 10.1016/j.solmat.2019.110107,

which has been published in final form at https://dx.doi.org/10.1016/j.solmat.2019.110107 @ https://dx.doi.org/10.1016/j.solmat.2019.110107. This manuscript version is made available under the CC-BY-NC-ND 4.0 license http://creativecommons.org/licenses/by-nc-nd/4.0/ 


\title{
Development of low-melting point molten salts and detection of solid-to-liquid transitions by alternative techniques to DSC
}

María del Rocío Rodríguez-Laguna*1, ${ }^{\text {, Pedro Gómez-Romero*1 }}{ }^{* 1}$ Clivia M. Sotomayor Torres ${ }^{1,3}$, Ming-Chang Lu ${ }^{4}$ and Emigdio Chávez-Ángel*1

[1] Catalan Institute of Nanoscience and Nanotechnology (ICN2), CSIC and BIST, Campus UAB, Bellaterra, 08193 Barcelona, Spain

[2] Departament de Química, Universitat Autònoma de Barcelona, Cerdanyola del Vallès, 08193 Barcelona, Spain

[3] ICREA, Pg. Lluís Companys 23, 08010 Barcelona, Spain

[4] Department of Mechanical Engineering, National Taiwan University, Taipei, 10617 Taiwan

*Corresponding authors: rodriguez3laguna@gmail.com; pedro.gomez@icn2.cat, emigdio.chavez@icn2.cat

Keywords: Solar thermal conversion, molten salts, low melting point, heat transfer fluids, thermal conductivity, Raman spectroscopy, thermal energy storage.

\begin{abstract}
The 'Solar salt' $\left(60 \% \mathrm{NaNO}_{3}-40 \% \mathrm{KNO}_{3}\right.$, wt. \%) is the most used heat transfer and storage material in high temperature CSP systems. The main drawback is its high melting temperature of $228{ }^{\circ} \mathrm{C}$, which requires extra-energy to keep it in the liquid state and avoid damage to pipes at low temperatures. Multi-component salts are combinations of different cations and anions. The difference in size of the ions hinders the crystallization of the material and provides lower melting temperatures. Multi-component salts are considered in this study to replace simpler combinations, such as binary and ternary eutectic mixtures. Herein, we report on two novel six-component nitrates with a melting temperature of $60-75{ }^{\circ} \mathrm{C}$ and a thermal stability up to $500{ }^{\circ} \mathrm{C}$ under a linear heating program in $\mathrm{N}_{2}$ atmosphere. Properties such as the thermal conductivity in solid and molten state, heat capacity and vibrational spectra were evaluated. The study of the thermal behaviour of these materials using differential scanning calorimetry was insufficient, hence alternative and complementary techniques were used, such as: the three-omega technique, optical transmission and Raman spectroscopy. Multi-component salts were found to solidify as amorphous solids even at slow cooling rates and water was found to behave as a catalyst of crystallization.
\end{abstract}




\section{Introduction}

Solar thermal conversion is now recognized as the soundest way to produce ecofriendly electrical energy $[1,2]$. The growing interest in this technology has opened new branches in the areas of heat transfer fluids (HTFs) and thermal energy storage (TES) materials [3-6]. In towerand dish-type solar thermal power plants, temperatures higher than $1000{ }^{\circ} \mathrm{C}$ can be reached $[7,8]$. Consequently, these high-temperature collectors require fluids with high thermal stability to effectively absorb this concentrated solar energy and deliver it to a heat exchanger or to a heat storage tank, without decomposing. Furthermore, a low melting point fluid is essential to reduce the operational costs of heating the fluid at night to avoid it freezing [9]. A fluid with a wide operational temperature range is beneficial both for energy conversion and for energy storage. Thus, producing high-temperature steam will substantially increase the efficiency of the steam turbine (Carnot's theorem) and that of the overall energy conversion. And in terms of sensible energy storage, a larger temperature difference in the storage system will result in a significantly increased specific storage capacity. [10,11]

In this sense, molten salts are best positioned to be used as heat transfer fluids (HTF) and thermal energy storage (TES) materials in concentrated solar power (CSP) technology $[12,13]$. In fact, molten salts are the most widespread storage materials in commercial CSP and can be used as direct and indirect heat storage [13]. They are defined as ionic compounds that melt at high temperatures $\left(\approx 200-1000^{\circ} \mathrm{C}\right)$ and form homogeneous and stable liquids. They include, among others, nitrates, nitrites, chlorides, hydroxides, carbonates and their mixtures $[1,14-$ 23]. Among them, nitrates show the most desirable features including non-toxicity, low corrosion, low vapor pressure and a suitable combination of high thermal stability and medium-melting temperature. Other advantage of these types of fluids is the possibility of developing mixtures with a lower melting point than their individual components (eutectics).

A non-eutectic binary salt mixture of $\mathrm{NaNO}_{3}-\mathrm{KNO}_{3}$ (60-40 wt.\%) [24] is the most widely used HTF/TES material in solar power towers. It is thermally stable up to $560{ }^{\circ} \mathrm{C}$, however, it has a medium-high melting point of $228^{\circ} \mathrm{C}$. Another example is a ternary mixture of carbonates with a high melting point of $400{ }^{\circ} \mathrm{C}$ [25], the lowest for a carbonate-based mixture. The main drawback of molten salts as storage medium is their high freezing points. Currently, trace heating systems and tank heaters have to be installed to reduce thermal gradient and minimize freezing risks. As a consequence, unaffordable parasitic consumptions are generated to maintain the salts in a liquid state [13]. In this sense, the development and use of novel composition of molten salts with lower melting points can reduce dramatically these costs and, as a consequence, improve the overall efficiency of the CSP system.

In this work, two novel molten salts with significantly low melting points and composed of $\mathrm{LiNO}_{3}-\mathrm{NaNO}_{3}-\mathrm{KNO}_{3}-\mathrm{CsNO} \mathrm{CN}_{3}-\mathrm{Ca}\left(\mathrm{NO}_{3}\right)_{2}-\mathrm{Al}\left(\mathrm{NO}_{3}\right)_{3}$ and $\mathrm{LiNO}_{3}-\mathrm{NaNO}_{3}-\mathrm{KNO}_{3}-\mathrm{CsNO}{ }_{3}-\mathrm{Ca}\left(\mathrm{NO}_{3}\right)_{2}-\mathrm{RbNO}_{3}$, respectively, are proposed and studied. They have a melting onset below $75^{\circ} \mathrm{C}$ and a thermal stability above $500{ }^{\circ} \mathrm{C}$ under a linear heating program of $10{ }^{\circ} \mathrm{C} / \mathrm{min}$. The thermal conductivity, melting temperature, specific heat capacity and vibrational spectra of the salts were evaluated. The results reveal the potential of these salts to be used as heat transfer fluids and thermal energy storage materials in CSP technology.

These new molten salts are six-component multi-cationic nitrates. It is known that the combination of cations with different charges and sizes hinders the crystallization of the material $[26,27]$. Therefore, molten salt mixtures with five or more components often show a 
lower melting point than binary or ternary compositions. However, the determination of the solid-to-liquid transition of these materials can be complex, due to several factors affecting their internal structure. To deepen into the thermal behavior of the materials, complementary and alternative techniques to the conventional differential scanning calorimetry (DSC) has been used. Some authors have used a capillary melting point apparatus to determine the solidliquid phase transition [16]. However, these measurements are performed by image processing or eye observation, which are insufficiently accurate. To meet the challenge of determining the solid-to-liquid phase transition of molten salts, we have used, and report here, the following techniques: i) automatized optical transmission method, ii) the threeomega $(3 \omega)$ technique and iii) Raman spectroscopy. All yielded similar results and agree with the melting temperature recorded by the naked eye, while providing a more reliable and objective determination of the melting range. Furthermore, these techniques provide important extra information regarding the thermal behavior of the mixtures and are proposed here as useful techniques for melting point and related phase-change studies. Other multicationic nitrate combination known as 'Halotechnics SS-500' [16] was also prepared for comparison with the new compositions and to complement the available data of the salt in the literature.

The specific heat, thermal stability and low melting point of these mixtures make them potentially good candidates for heat transfer and storage applications. Their increased range of operational temperature places them in a favorable position with respect to conventional HTFs for cost-effective concentrated solar power (CSP) technology. Furthermore, the characterization of these new materials has allowed us to get further insight on the behavior of multi-component salts, such as their glassy nature and water impact on their crystallization. On top of that, three different techniques have been used for the very first time to detect solid to liquid phase transitions as an alternative to DSC. 


\section{Materials and methods}

Reagents and chemicals were supplied by Sigma Aldrich Chemical Co. Ltd. (www.sigmaaldrich.com) and Acros Organics (www.acros.com). Aluminum nitrate nonahydrate $(98 \%)$, cesium nitrate $(99 \%)$, potassium nitrate $(99.0+\%)$, rubidium nitrate $(99.7 \%)$ and sodium nitrate (98\%) were obtained from samples with ACS reagent grade from Sigma Aldrich. Extra pure calcium nitrate tetrahydrate $(99+\%)$ and lithium nitrate $(99 \%)$ were obtained from Acros Organics, ACS reagent grade. Pure salts were dried and stored in a vacuum desiccator for at least 24 hours previous to the preparation of the mixtures, with the exception of $\mathrm{Al}\left(\mathrm{NO}_{3}\right)_{3} \cdot 9 \mathrm{H}_{2} \mathrm{O}$ and $\mathrm{Ca}\left(\mathrm{NO}_{3}\right)_{2} \cdot 4 \mathrm{H}_{2} \mathrm{O}$ which were used as provided. No additional purification of the salts was needed.

\section{Molten salts preparation}

Molten salts were prepared by the direct mixing of the pure chemicals in the proportions given in Table 1

Table 1 Compositions of molten salts indicating the weight percentage (\%) of individual components

\begin{tabular}{|c|c|c|c|c|c|c|c|}
\cline { 2 - 8 } \multicolumn{1}{c|}{} & \multicolumn{7}{c|}{ Components (\%) } \\
\hline Sample name & $\mathrm{LiNO}_{3}$ & $\mathrm{NaNO}_{3}$ & $\mathrm{KNO}_{3}$ & $\mathrm{CsNO}_{3}$ & $\mathrm{Ca}(\mathrm{NO})_{2}$ & $\mathrm{RbNO}_{3}$ & $\mathrm{Al}_{\left(\mathrm{NO}_{3}\right)_{3}}$ \\
\hline $\begin{array}{c}\text { Halotechnics SS- } \\
500(\mathrm{Q}) \text { [16] }\end{array}$ & 8 & 6 & 23 & 44 & 19 & - & - \\
\hline Senary 1 (S-Al) & 7.6 & 5.7 & 21.5 & 40.9 & 17.8 & - & 6.6 \\
\hline Senary 2 (S-Rb) & 7.6 & 5.7 & 21.8 & 41.6 & 15.7 & 7.6 & - \\
\hline
\end{tabular}

Hereafter, for convenience, sample names will be shortened. The quinary salt 'Halotechnics SS500 ' will be labeled as ' $\mathrm{Q}$ ' and the senary salts 1 and 2 will be named in the text as ' $\mathrm{S}$ - $\mathrm{Al}$ ' and ' $\mathrm{S}$ $\mathrm{Rb}^{\prime}$, respectively.

The composition of the two novel salts, S-Al and S-Rb, was selected based on the quinary salt ' $Q$ '. The proportion between the five original components (lithium, sodium, potassium, cesium and calcium nitrates) was maintained constant in the new compositions. The extra component, rubidium and aluminum nitrates, was added in a similar amount than lithium nitrate. To prepare approximately $6 \mathrm{~g}$ of $\mathrm{S}-\mathrm{Rb}$, the following amounts were added into an alumina crucible: $1.384 \mathrm{~g}$ of $\mathrm{Ca}\left(\mathrm{NO}_{3}\right)_{2} \cdot 4 \mathrm{H}_{2} \mathrm{O}, 2.220 \mathrm{~g}$ of $\mathrm{CsNO}_{3}, 1.161 \mathrm{~g}$ of $\mathrm{KNO}_{3}, 0.407 \mathrm{~g}$ of $\mathrm{LiNO}_{3}, 0.406 \mathrm{~g}$ of $\mathrm{RbNO}_{3}$ and $0.307 \mathrm{~g}$ of $\mathrm{NaNO}_{3}$. The preparation of $6 \mathrm{~g}$ of S-Al consisted of weighting the following amounts: $1.381 \mathrm{~g}$ of $\mathrm{Ca}\left(\mathrm{NO}_{3}\right)_{2} \cdot 4 \mathrm{H}_{2} \mathrm{O}, 2.210 \mathrm{~g}$ of $\mathrm{CsNO}_{3}, 1.159 \mathrm{~g}$ of $\mathrm{KNO}_{3}, 0.407 \mathrm{~g}$ of $\mathrm{LiNO}_{3}, 0.623 \mathrm{~g}$ of $\mathrm{Al}\left(\mathrm{NO}_{3}\right)_{3} \cdot 9 \mathrm{H}_{2} \mathrm{O}$ and $0.306 \mathrm{~g}$ of $\mathrm{NaNO}_{3}$.

In order to obtain a homogeneous mixture, the samples were then located in a muffle furnace (Barnstead-Thermolyne muffle furnace, model No. FB1410M-33) and heated up to $400{ }^{\circ} \mathrm{C}$ at 10 ${ }^{\circ} \mathrm{C} / \mathrm{min}$, followed by a $2 \mathrm{~h}$-isotherm and natural cooling. All the molten salts showed a white or translucent white homogeneous appearance after this thermal treatment. Naked-eye inspections showed no trace of yellow in the mixture, indicating the absence of nitrites. This was also corroborated by X-Ray diffraction (XRD) (see supporting information). The molten salts were then kept in a vacuum desiccator prior to measurements. 
The schematic diagram of the preparation of the salts is shown in Figure 1, which includes the following steps:

1. Drying the pure salts in a vacuum desiccator for at least $24 \mathrm{~h}$.

2. Direct mixing of the pure salts in an alumina crucible favoring the direct contact of the salts. Covering the crucible with a lid.

3. Introduction of the crucible inside a muffle furnace, where the sample is heated at 10 ${ }^{\circ} \mathrm{C} / \mathrm{min}$ up to $400{ }^{\circ} \mathrm{C}$ for 2 hours.

4. Allow the sample to cool down naturally.

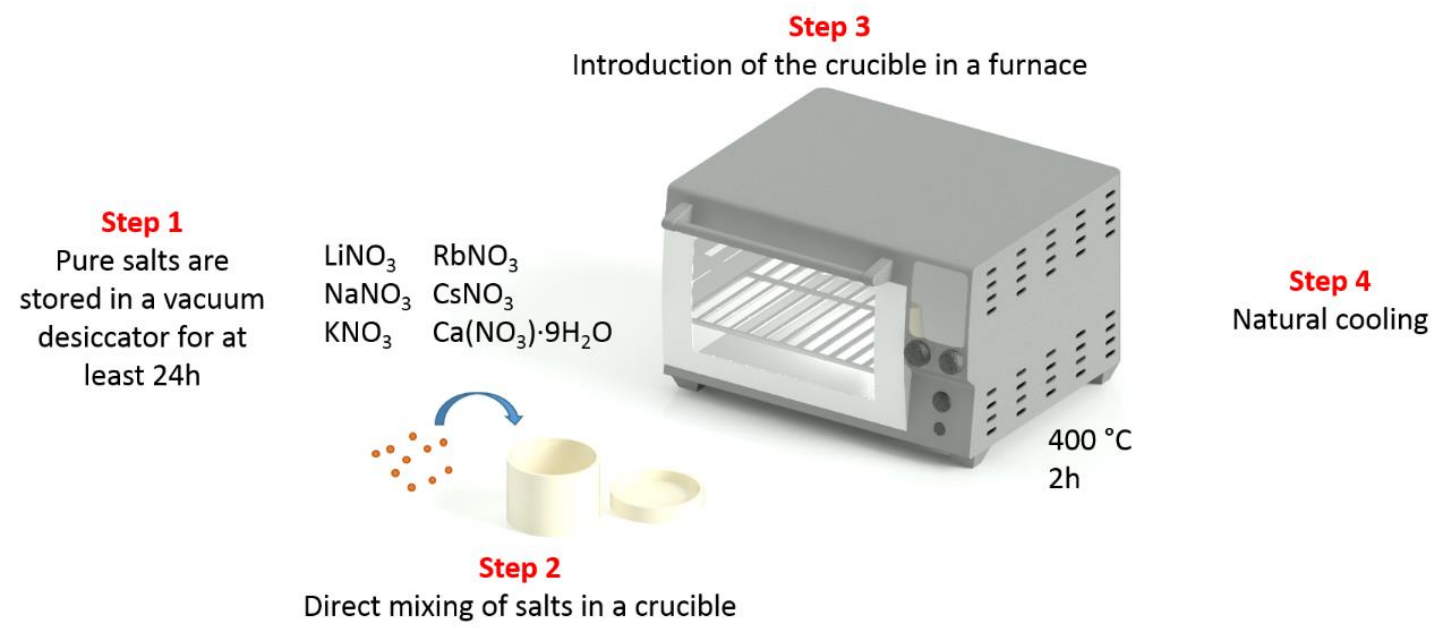

Figure 1. Schematic diagram of the preparation of the multi-component salts (particular example: sample S-Rb).

The thermal behavior of the molten salts was studied by DSC (PerkinElmer DSC 8000) from room temperature up to $300{ }^{\circ} \mathrm{C}$ at different heating rates, using sealed aluminum pans in 20 $\mathrm{ml} / \mathrm{min}$ nitrogen-flow atmosphere. Specific heat capacity was measured on a Mettler Toledo DSC822e 1 STAR $^{\mathrm{e}}$ system. The sapphire method was used and the heating program consisted on 'iso-dyn-iso' steps from $290-320{ }^{\circ} \mathrm{C}$ in $60 \mathrm{ml} / \mathrm{min}$ nitrogen-flow atmosphere. An extended explanation of the experimental conditions is included in the supporting information. Thermogravimetric data was obtained from a Pyris $1 \mathrm{TGA}$ (PerkinElmer) at $10{ }^{\circ} \mathrm{C} / \mathrm{min}$ from room temperature to $700{ }^{\circ} \mathrm{C}$ in a $20 \mathrm{ml} / \mathrm{min}$ flow $\mathrm{N}_{2}$ atmosphere. The thermal conductivity from solid to liquid states was measured by the $3 \omega$ technique in an in-house built set-up. The details of the equipment and the measurement are detailed in an earlier work [28]. Raman spectra were recorded with a HORIBA Jobin Yvon T64000 Raman spectrometer used in single grating mode with a spectral resolution better than $0.4 \mathrm{~cm}^{-1}$. The salts were placed in a cryostat (Linksys32, Linkam Scientific Instruments) in a helium static atmosphere of $1 \mathrm{~atm}$. All Raman measurements were carried out by focusing a diode laser $\left(\lambda_{0}=532 \mathrm{~nm}\right)$ with $50 \mathrm{x}$ long working distance microscope objective. The power of the laser was kept below $2 \mathrm{~mW}$ to avoid self-heating effects.

The transmission of a $635 \mathrm{~nm}$ red diode laser through two glass cuvettes, one empty and an identical cuvette filled with the sample, was recorded from room temperature to $140{ }^{\circ} \mathrm{C}$. The optical transmission measurements were performed in air atmosphere. The sample was heated using a hot plate inside an insulating box and the temperature was set manually. An extended description of the set-up is included in the supporting information.

Prior to the characterization by DSC, the $3 \omega$ technique, transmission and Raman spectroscopy, the samples were melted using a heat gun above $100^{\circ} \mathrm{C}$. 


\section{Results and discussion}

\section{Differential scanning calorimetry and thermogravimetric analyses}

DSC curves of samples S-Al, S-Rb and Q were recorded with a thermal cycle of 10, 30 and 50 ${ }^{\circ} \mathrm{C} / \mathrm{min}$ as shown in Figure 2a-c. Multiple scan rates were applied to test the sensitivity of the equipment because no thermal events were observed under standard conditions $\left(10^{\circ} \mathrm{C} / \mathrm{min}\right)$. In addition, by varying the scan rate, temperature-time-dependent transitions can be easily identified, such as the glass transition. Hereafter, the temperature of first deviation of the baseline will be defined as the onset temperature of the phase transition (melting, crystallization, evaporation, etc.).

As can be observed in Figure $\mathbf{2 a}$, the DSC curve of sample S-Al shows no clear transitions during the heating step at the scan rate of $10^{\circ} \mathrm{C} / \mathrm{min}$, but an exothermic peak appeared during cooling at approx. $93{ }^{\circ} \mathrm{C}$. These results indicate that the sample is amorphous during the first heating at $10{ }^{\circ} \mathrm{C} / \mathrm{min}$, hence, no phase change is observed. During the cooling step the salt crystallizes. At higher heating rates, a clear endothermic transition (peak onset $\approx 75{ }^{\circ} \mathrm{C}$ ) can be observed, as well as the corresponding exothermic peak during cooling. These peaks may correspond to the melting and crystallization of the salt, respectively, matching what was observed with the naked eye. The onset of the endothermic transition shifts only by $2-5{ }^{\circ} \mathrm{C}$ over a heating rate range of $30-50{ }^{\circ} \mathrm{C} / \mathrm{min}$, which indicates it is not a kinetic process (neither glass transition, nor decomposition), reinforcing the idea of a melting transition.

Interestingly, at the heating rate of $30{ }^{\circ} \mathrm{C} / \mathrm{min}$ a subtle exothermic peak can be observed just before the endothermic peak, this exothermic peak is much better defined in the $50{ }^{\circ} \mathrm{C} / \mathrm{min}$ curve. Multi-component systems have difficulties in ordering and tend to form glasses, hence this exothermic transition can be attributed to the crystallization of a residual amorphous portion of the sample.

In contrast, samples $\mathrm{Q}$ and $\mathrm{S}-\mathrm{Rb}$ did not show thermal transitions during the thermal cycle at any scan rate (Figure $\mathbf{2} \mathbf{b}$-c), with the exception of an endothermic peak at low temperatures (onset $\approx 37^{\circ} \mathrm{C}$ ), which appears only during the first heating cycle of the sample, see Figure $2 \mathrm{c}$ $\left(10^{\circ} \mathrm{C} / \mathrm{min}\right)$. The rest of the curves correspond to pre-heated samples.

The hygroscopic nature of the salts, together with the mass loss observed at low temperatures in the thermograms (Figure $\mathbf{2 d}$ ), indicate that the endothermic peak at $\approx 37{ }^{\circ} \mathrm{C}$ corresponds to the vaporization of absorbed water in the sample. Pierced lids were used to avoid pressure problems or bursting. Consequently, as expected, no exothermic peak is observed during the cooling step.

The absence of thermal events in the calorimetric curves of samples $Q$ and $S-R b$ can be explained by taking into consideration the nature and internal structure of multi-component mixtures. The presence of cations of different sizes in the mixture hinders the crystallization of the material, thus promoting the amorphous state. The results obtained from X-Ray diffraction (XRD) support this idea (see supporting information for more details). The XRD analyses were performed at room temperature as a function of time and humidity. X-ray diffraction patterns show that samples $\mathrm{Q}$ and $\mathrm{S}-\mathrm{Rb}$ do not crystallize right after the melting, but after 1 or 2 hours. On the contrary, S-Al presents a faster crystallization. The effect of humidity was also studied by XRD. The exposure to a humid environment favors the crystallization of $\mathrm{Q}, \mathrm{S}-\mathrm{Al}$ and S-Rb. Water facilitates the movement of the ions within the mixture, acting as a lubricant and catalyst for crystallization. 
A comparative study of the thermal stability of the new compositions was performed by TGA, as shown in Figure $\mathbf{2 d}$. The three samples exhibited an initial weight loss at low temperature, which is ascribed to the evaporation of water absorbed by the material. Nitrates are in general very hygroscopic compounds. Therefore, the control of the storage conditions and atmospheric humidity during the preparation of the samples for the analysis is crucial to avoid water absorption. Thermogravimetric analyses on salts S-Al and S-Rb were performed in our laboratory, hence the amount of absorbed water is similar in these samples. The thermogravimetric data from salt $Q$ were taken from the literature [16]. A significant weight loss was observed for the three samples in the range of 550-700 ${ }^{\circ} \mathrm{C}$, which is attributed to the decomposition of the salts. Under the same conditions, S-Al was thermally more stable than $\mathrm{S}$ $\mathrm{Rb}$. At $602{ }^{\circ} \mathrm{C}, \mathrm{S}-\mathrm{Rb}$ had already lost $2.5 \%$ of its weight, in contrast, S-Al reached the same loss (2.5\% in weight) at $606{ }^{\circ} \mathrm{C}$. Raade and Padowitz [16] reported a 2.5 wt. \% loss for the quinary mixture at $599{ }^{\circ} \mathrm{C}$ in $\mathrm{N}_{2}$ atmosphere, at a heating rate of $10{ }^{\circ} \mathrm{C} / \mathrm{min}$.

It should be mentioned that these experimental datasets are not sufficient to predict the longterm thermal stability of the salts. However, running a linear heating rate program to the samples under the same experimental conditions permits a relative evaluation of their thermal stability.

To completely characterize the thermal behavior of multi-component salts, complementary and alternative techniques were used, namely, three omega technique (thermal conductivity), optical transmission and Raman spectroscopy. Multi-component mixtures have not yet been studied in depth. As mention above, the presence of a variety of species with different sizes and features hinders the crystallization of the material, nevertheless, several factors can modulate the crystallization e.g. cooling rate, presence of water, time. The research done in multi-component salts for thermal solar applications abstains from giving a complete view of the thermal behavior and internal structure of the samples $[15,16,19]$. 

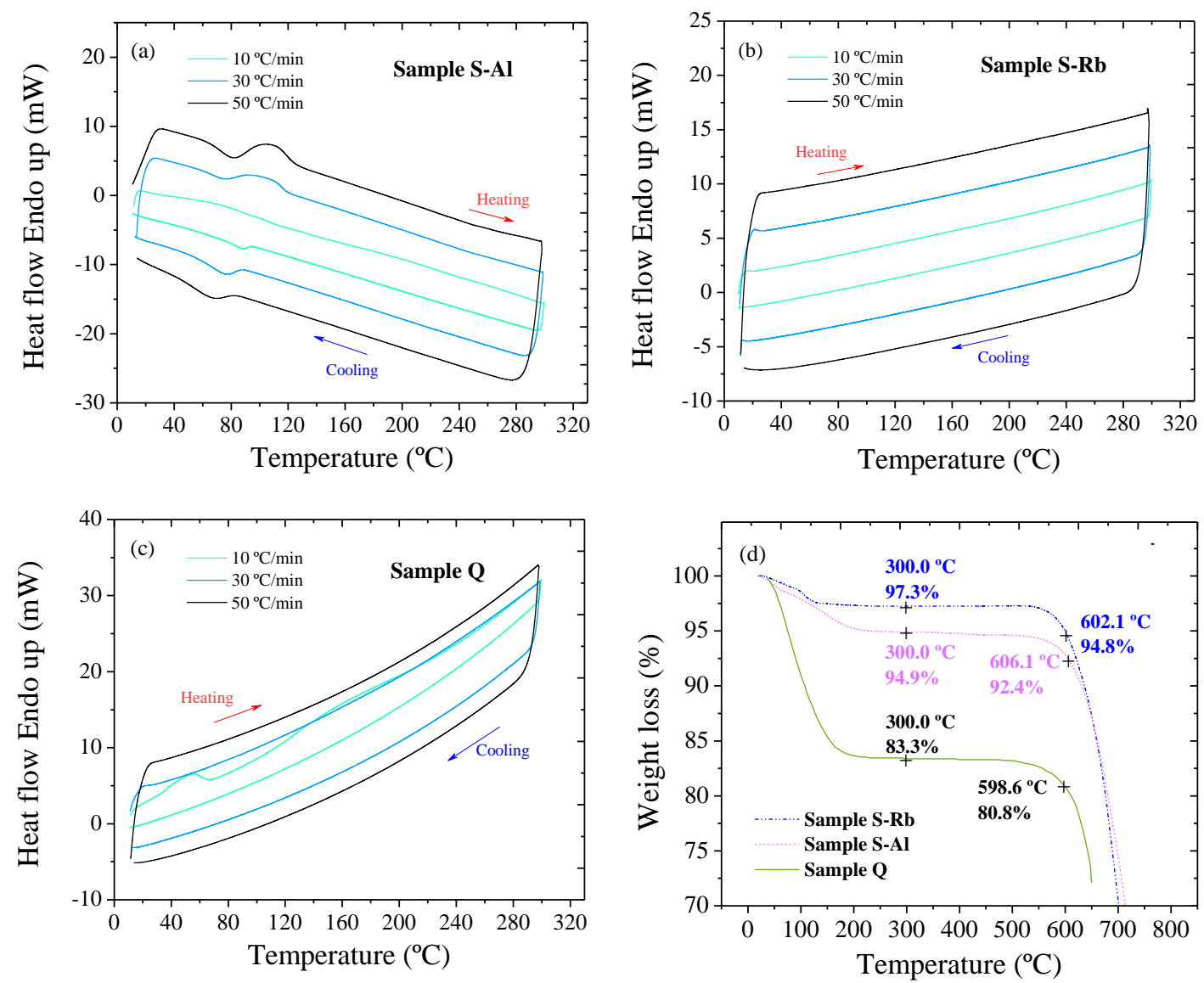

Figure 2. Calorimetric and thermogravimetric curves of the senary compositions and the previously reported quinary [16]. (a) Calorimetric curves of S-Al at 10,30 and $50{ }^{\circ} \mathrm{C} / \mathrm{min}$, cooling and heating. (b) Calorimetric curves of S-Rb at 10, 30 and $50{ }^{\circ} \mathrm{C} / \mathrm{min}$, cooling and heating. (c) Calorimetric curves of $Q$ at 10,30 and $50^{\circ} \mathrm{C} / \mathrm{min}$, cooling and heating. (d) Thermogravimetric curves of the two senary salts and sample $Q$ at a heating rate of $10^{\circ} \mathrm{C} / \mathrm{min}$ in $\mathrm{N}_{2}$ atmosphere. The thermogravimetric curve from salt $\mathrm{Q}$ was taken from the literature (data from ref. [16]).

These mixtures present a number of properties that change abruptly when turning from solid to liquid states, such as sample transparency, thermal conductivity and internal vibrational energies. The transparency variation of the molten material in solid and liquid states was used to determine the phase change by optical transmission. In this sense, our findings open the possibility to use alternative methods to DSC to gain thermal knowledge on molten salts and related samples.

\section{Optical transmission and thermal conductivity}

The variation in transparency of the salts in the solid and liquid states, from white to transparent, respectively, allowed the detection of the phase change by optical transmission. Figure $\mathbf{3 d}$ shows the appearance of the $\mathrm{S}-\mathrm{Rb}$ salt in solid (white) and liquid (transparent) states. The thermal conductivity was measured from room temperature to $140{ }^{\circ} \mathrm{C}$. Figure 3 shows a representation of the thermal conductivity and optical transmission data of S-Al, S-Rb and Q as a function of temperature. In all three cases, a decrease on the thermal conductivity can be observed as the temperature increases. On the contrary, the optical transmission increased as solid to liquid phase change occurred. The onset temperature of the phase change from solid to liquid derived from optical transmission and thermal conductivity data were found to be in good agreement. 
Figure 3a shows the transmission and thermal conductivity curves of sample S-Al as a function of temperature. As can be seen, the light started to be transmitted above $60{ }^{\circ} \mathrm{C}$, in agreement with DSC data. The transmission increased up to a maximum at $96{ }^{\circ} \mathrm{C}$ and above this temperature the transmission remained constant. On the other hand, a drop in thermal conductivity ( $k$ ) was more difficult to observe. It can be seen that above $76{ }^{\circ} \mathrm{C}$ there was an important change in the thermal conductivity, which perfectly matched the corresponding transmission and DSC data.

The thermal conductivity of sample S-Rb underwent a noticeable drop in $k$ values starting at 60 ${ }^{\circ} \mathrm{C}$, as shown in Figure $3 \mathrm{~b}$. Transmission also started to increase at $60{ }^{\circ} \mathrm{C}$. Furthermore, $k$ and transmission values remained constant above $100^{\circ} \mathrm{C}$, indicating the end of the phase change.

As shown in Figure 3c, there was a drastic change on the transmission of sample $Q$ above 60 ${ }^{\circ} \mathrm{C}$, which is also the temperature at which the thermal conductivity begins to fall gradually. This change in transmission and thermal conductivity indicates the starting temperature of the melting, which is in complete agreement with the value reported by Raade and Padowitz [16]. As can be observed, $k$ and transmission values remained constant above $100{ }^{\circ} \mathrm{C}$.

The decrease in transmission observed in Figure $3 \mathbf{b}$ from 25 to $45^{\circ} \mathrm{C}$ is due to water absorption by the salt. The presence of water has been proven to favor the crystallization of the salt. Consequently, the initial state of the samples was semi-crystalline and translucent in some of the cases due to the presence of water. This explains the change in transparency of the sample $\mathrm{S}-\mathrm{Rb}$ to more opaque with time, as waters evaporates, until the material changed to the liquid state. The optical transmission measurements were performed in air atmosphere without controlling the humidity. The temperature of the hot plate used to heat the sample was set manually. Consequently, the required time gap for the temperature to stabilize each time, differs from one measurement to another. Hence, the absorption of water also varied from one sample to another.

Regarding thermal conductivity, we can conclude that there is not a significant difference in their values, at a given temperature, for the different molten salts. As can be seen in Figure 3, $k$ values vary from 0.345 to $0.358 \mathrm{~W} \mathrm{~m}^{-1} \mathrm{~K}^{-1}$ which are in the same range reported previously for other molten salts [20]. The average thermal conductivity of these salts in the liquid state is slightly smaller than that of the Solar salt $\left(\approx 0.520 \mathrm{~W} \mathrm{~m}^{-1} \mathrm{~K}^{-1}\right)$ [29] and similar or even larger than that of Hitec $\left(\approx 0.350 \mathrm{~W} \mathrm{~m}^{-1} \mathrm{~K}^{-1}\right)[30]$. 

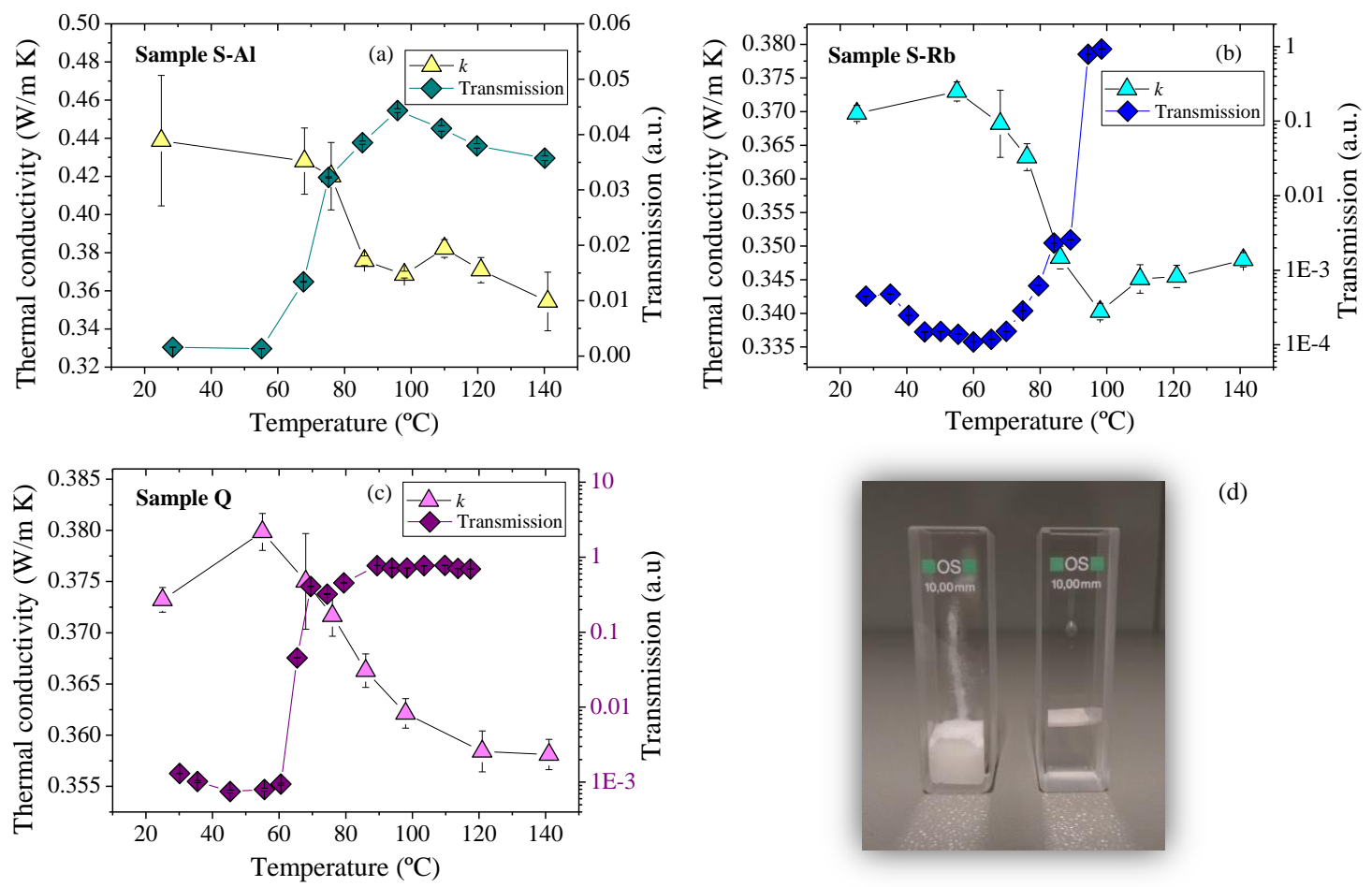

Figure 3. Optical transmission (full diamonds) and thermal conductivity (full triangles) of samples S-Al (a), S-Rb (b) and $\mathrm{Q}(\mathrm{c})$ as a function of temperature and (d) an image of sample S-Rb in solid (white) and liquid (transparent) states.

\section{Specific heat capacity}

The specific heat capacity (Cp) was determined using the Sapphire method (ASTM standard E1269 - 11) measured by DSC. The Cp measurement of each salt was repeated at least three times and the average values are shown in Figure 4, which shows the specific heat capacity of salts $\mathrm{Q}, \mathrm{S}-\mathrm{Al}$ and $\mathrm{S}-\mathrm{Rb}$ as a function of temperature from $290-320^{\circ} \mathrm{C}$. Cp values of salt $\mathrm{Q}$ were taken from the literature [19] to compare with the new compositions. The measured specific heat capacity of the new salts is close to that of the Halotechnics SS-500 (sample Q) and $\mathrm{NaKCsNO}_{3}$ salts (1.20 and $1.18 \mathrm{~J} \mathrm{~g}^{-1} \mathrm{~K}^{-1}$, respectively) [19]. These results support the potential of these salts to be used as thermal energy storage materials in CSP technology.

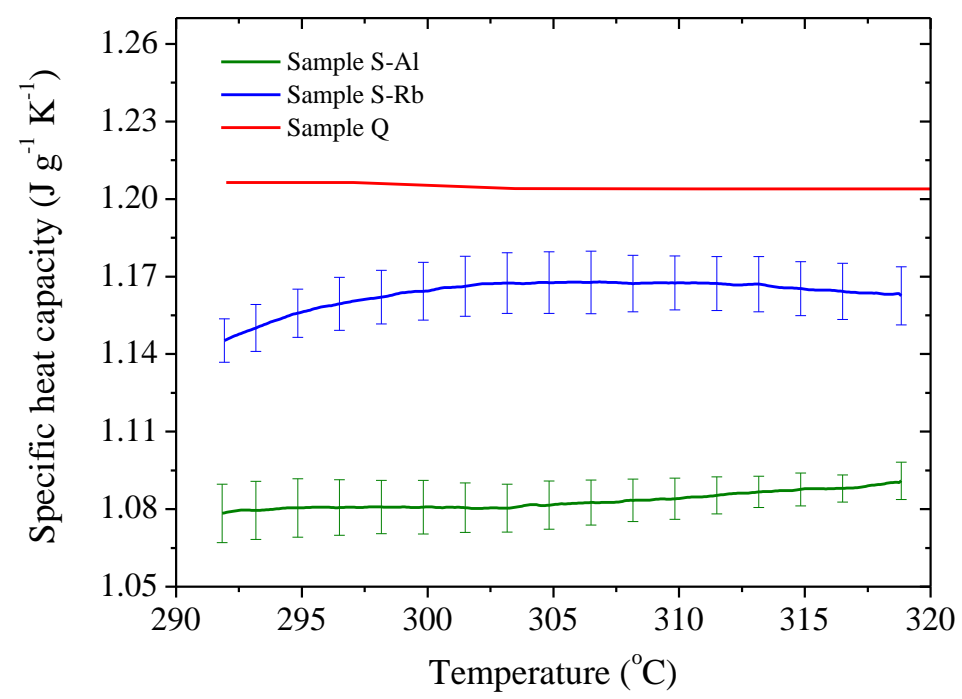

Figure 4. Specific heat capacity of samples S-Al, S-Rb (experimental data) and Q from reference [19] as a function of temperature. 


\section{Raman spectroscopy}

The Raman spectra of the samples were recorded as a function of temperature in steps of 10 ${ }^{\circ} \mathrm{C}$, approximately, from -10 to $149{ }^{\circ} \mathrm{C}$ at a scan rate of $2{ }^{\circ} \mathrm{C} / \mathrm{min}$. These data provided information on the melting onset and the internal structure of the mixtures as a function of temperature. The intense band at $\sim 1050 \mathrm{~cm}^{-1}$ is ascribed to a symmetric stretching mode of the nitrate ion, $\omega_{1}$, if $\mathrm{D}_{3 \mathrm{~h}}$ symmetry is assumed for the $\mathrm{NO}_{3}{ }^{-}$in the crystalline state, and no distortion of the geometry occurs, as Janz et al. assumed [31]. In addition, other very weak bands present at $\sim 1350,1380-1443$ and $1650 \mathrm{~cm}^{-1}$ have been associated to antisymmetric stretching modes and an overtone of a bending mode (scissoring) of the nitrate ion [31]. However, their low Raman activity makes them difficult to detect. Therefore, we based our study on the symmetric stretching mode of $\mathrm{NO}_{3}{ }^{-}$as a function of temperature.

Janz et al. reported that the internal modes of $\mathrm{NO}_{3}{ }^{-}$, such as $\omega_{1}$, are affected by the cationic environment. In fact, in pure salts this mode $\left(\omega_{1}\right)$ has been shown to be correlated with the polarizing power of the cationic species, e.g., in alkaline nitrates going from $\mathrm{Li}^{+}$to $\mathrm{Cs}^{+}, \omega_{1}$ decreases in frequency in a regular manner. Furthermore, in some alkaline binary mixtures, $\omega_{1}$ appears as an additive function of the pure salts $\omega_{1}$ frequencies multiplied by the fraction present [31].

In mixtures of nitrates of five or six cations of different sizes and charges, as is our case, it has been found that glassy structures are preferentially formed during rapid-cooling $[26,27]$. This is due to the inability of these ions to segregate into pure component crystals during cooling as they appear to be randomly mixed in the molten state [27]. Raman spectroscopy can also provide information about the amount of disorder in the structure. In glasses all bands appear broadened typically with linewidths in the range of $20 \mathrm{~cm}^{-1}$, which is an order of magnitude broader than that measured in ordered crystals [27].

\section{Sample S-Al}

Figure 5a shows the Raman spectra of sample S-Al as a function of temperature recorded with increasing temperature at a rate of $2{ }^{\circ} \mathrm{C} / \mathrm{min}$. As can be seen, at room temperature there is a band with a narrow linewidth $\left(\Delta \mathrm{E} \sim 3 \mathrm{~cm}^{-1}\right)$ at $\sim 1048 \mathrm{~cm}^{-1}$ and a small shoulder at higher frequencies. Both correspond to the stretching mode of $\mathrm{NO}_{3}{ }^{-}$. However, the narrow band at $1048 \mathrm{~cm}^{-1}$ corresponds to the salt in crystalline state whereas the shoulder can be associated with an amorphous domain that is formed due to the loss of water (it grows slightly from 30$54{ }^{\circ} \mathrm{C}$ ). This shoulder becomes smooth from $65^{\circ} \mathrm{C}$ to $96^{\circ} \mathrm{C}$. This can be explained as an ordering of the catiaonic environment due to the heating of the sample. Above $96{ }^{\circ} \mathrm{C}$ it becomes more intense again dominating the spectrum. It indicates the beginning of the melting. At $118{ }^{\circ} \mathrm{C}$ the peak at $1048 \mathrm{~cm}^{-1}$ is completely masked by the shoulder which has become a wider band, indicating that the phase change to liquid state has come to its end. This vibrational mode was also registered during the cooling of the salt at a rate of $2{ }^{\circ} \mathrm{C} / \mathrm{min}$, as shown in Figure $\mathbf{5 b}$. The spectra are dominated by a broad peak, indicating the amorphous nature of the salt. This illustrates the difficulty in ordering the multi-component mixtures, even at slow cooling rates $\left(2{ }^{\circ} \mathrm{C} / \mathrm{min}\right.$ ). A typical shift to higher frequencies is observed during cooling of the broad peak. Figure $\mathbf{5 c}$ shows the change in frequency as a function of temperature during cooling at a rate of $2{ }^{\circ} \mathrm{C} / \mathrm{min}$. 

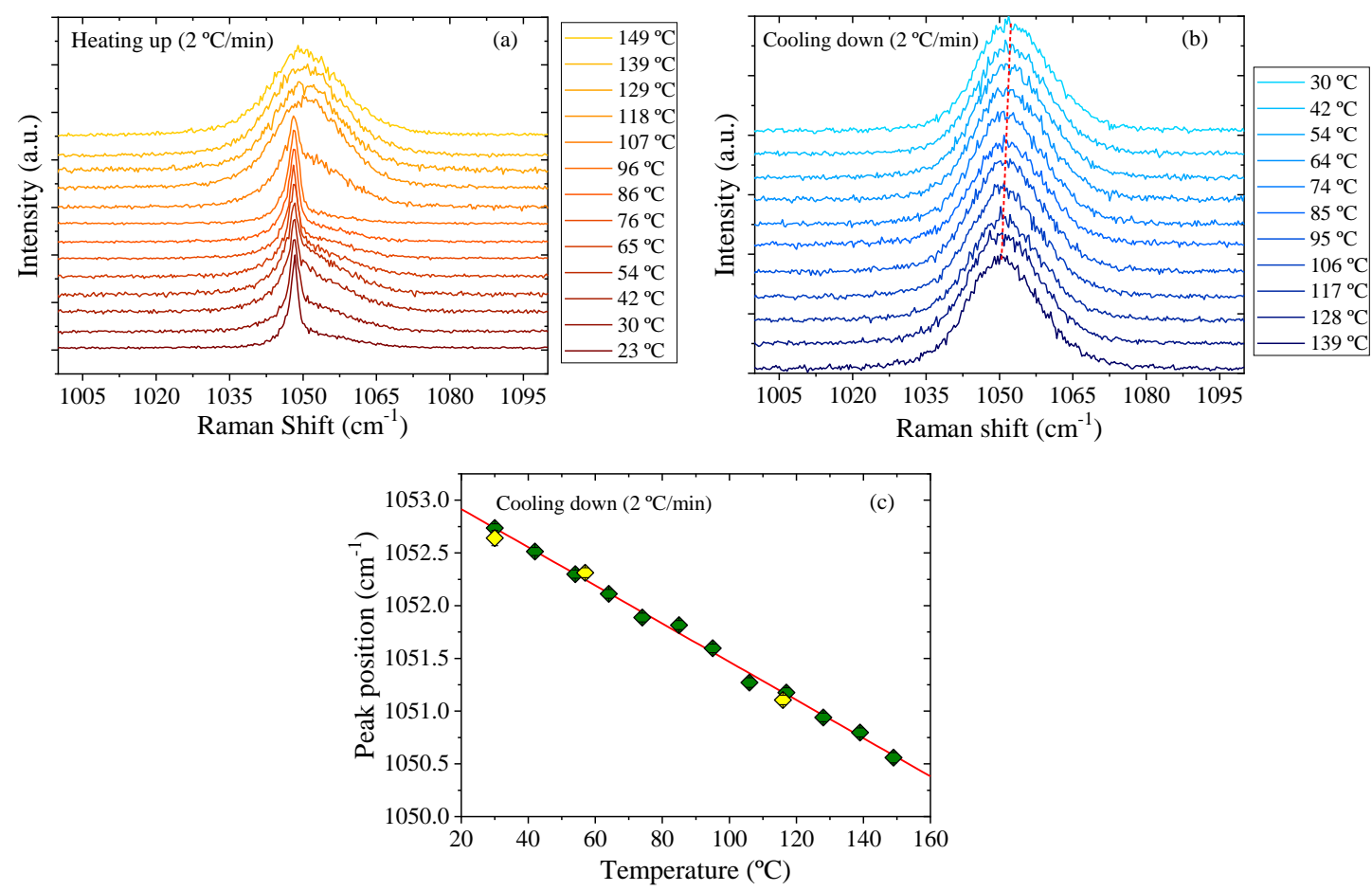

Figure 5. Raman spectra of sample S-Al under (a) heating at $2{ }^{\circ} \mathrm{C} / \mathrm{min}$ (b) cooling at $2{ }^{\circ} \mathrm{C} / \mathrm{min}$ and (c) peak position of the symmetric stretching $\mathrm{NO}_{3}{ }^{-}$mode as a function of temperature during cooling at $2{ }^{\circ} \mathrm{C} / \mathrm{min}$.

\section{Sample S-Rb}

The symmetric stretching band $\left(v \approx 1050 \mathrm{~cm}^{-1}\right)$ is shown in Figure 6a. The frequency and lineshape were tracked from room temperature to $110{ }^{\circ} \mathrm{C}$ at a heating rate of $2{ }^{\circ} \mathrm{C} / \mathrm{min}$. Both frequency and line-shape remained unchanged up to $60^{\circ} \mathrm{C}$ above which the band suddenly broadens. At that point the band broadened around $20 \mathrm{~cm}^{-1}$ indicating a disorder in the surroundings of the nitrate anion. This result points to a phase change from solid (crystal) to liquid state occurring between $60-72{ }^{\circ} \mathrm{C}$. The spectrum at $90{ }^{\circ} \mathrm{C}$ demonstrates that there are still solid (crystalline) domains, therefore, at $90{ }^{\circ} \mathrm{C}$ the salt is still not homogeneous, i.e. not completely molten. These values are in agreement with the data obtained from transmission and thermal conductivity vs $\mathrm{T}$. Figure $\mathbf{6} \mathbf{b}$ shows a slow crystallization taking place during cooling at $2{ }^{\circ} \mathrm{C} / \mathrm{min}$.

In Figure $\mathbf{6 b}$ the band is somehow distorted at certain temperatures. This is due to the kinetic nature of crystallization; crystals are growing in the material, but part of the salt is still in the liquid state. Temperatures labelled as ' $\mathrm{T}{ }^{\circ} \mathrm{C}-2^{2}$ ' correspond to domains with growing crystals visible with the camera, while the unlabeled temperature values correspond to liquid domains. As can be observed, in mixed domains $\left(\mathrm{T}^{\circ} \mathrm{C}-2\right)$ the spectrum shows two overlapped bands. The narrower band can be ascribed to the crystalline material and the broader band to the molten or amorphous fraction. 

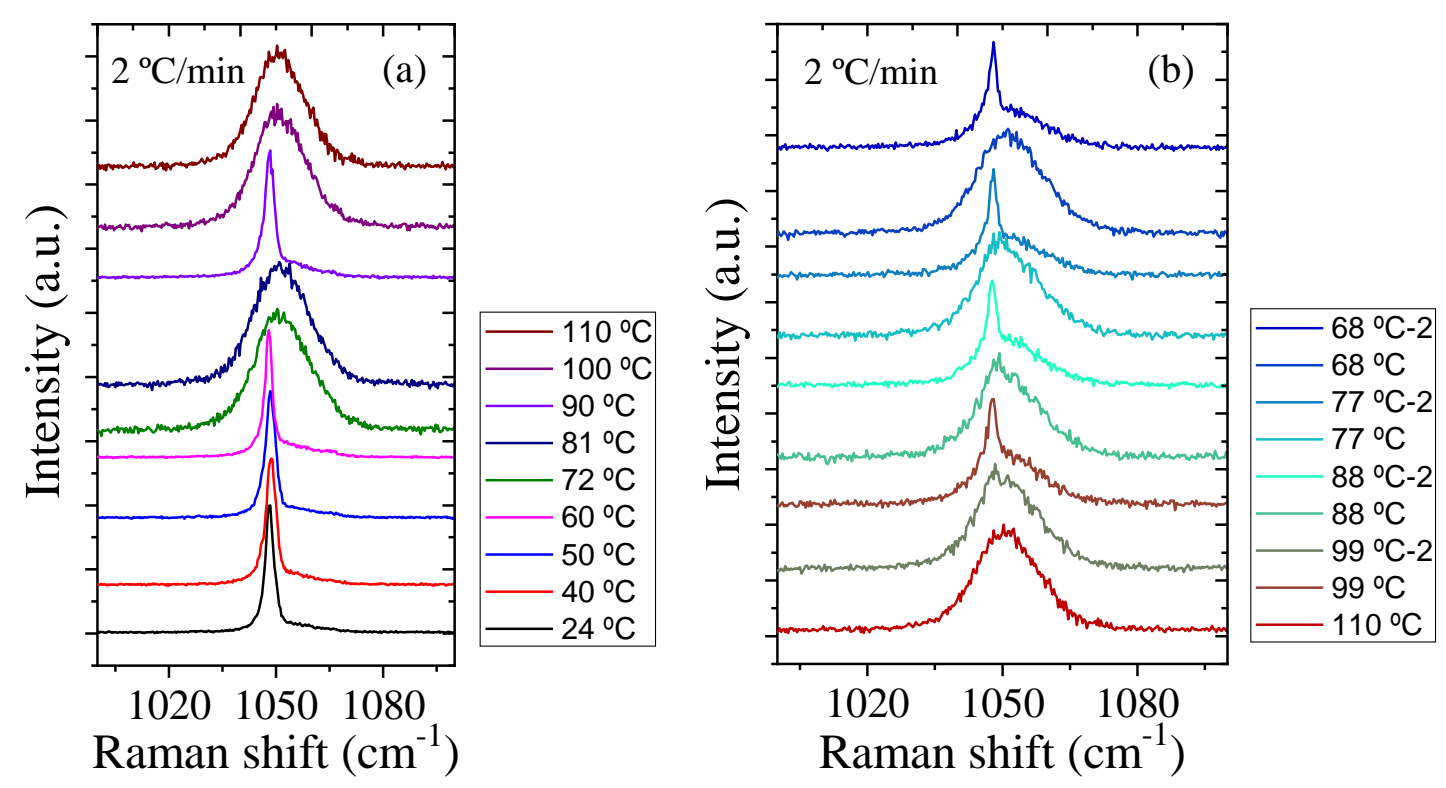

Figure 6. Raman scattering of sample $\mathrm{S}-\mathrm{Rb}$. The symmetric stretching $\mathrm{NO}_{3}{ }^{-}$mode intensity and linewidth are followed under heating (a) and cooling (b) both at a rate of $2{ }^{\circ} \mathrm{C} / \mathrm{min}$.

\section{Sample Q}

The symmetric stretching of $\mathrm{NO}_{3}^{-}$mode was recorded during heating and cooling at $2{ }^{\circ} \mathrm{C} / \mathrm{min}$ as a function of temperature, as shown in Figure 7. As can be seen the band showed a broad linewidth and line-shape over the entire temperature range. However, the typical shift to lower frequencies when increasing temperature as well as the opposite behavior during cooling can be observed in Figure 7c. The observed broad band at low temperatures indicates the amorphous nature of the sample in solid state. Unfortunately, the linewidth and line-shape remained unaltered when temperature is increasing (or decreasing), without a drastic change at any temperature. Therefore, no information corresponding to the solid to liquid phase change can be obtained analyzing these spectra. 

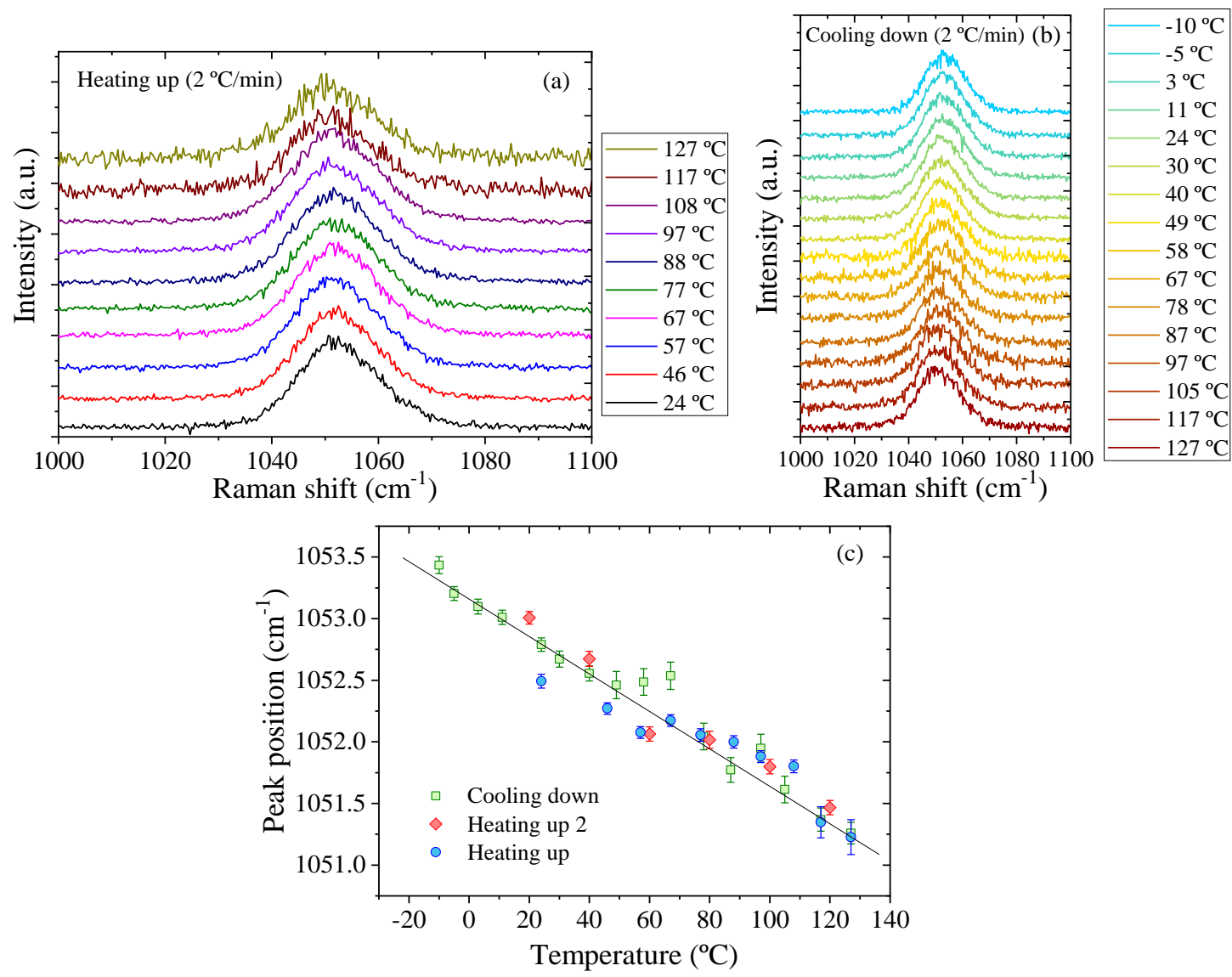

Figure 7. Raman spectra of the sample $Q$ at $2{ }^{\circ} \mathrm{C} / \mathrm{min}$ and peak position of the symmetric stretching mode of $\mathrm{NO}_{3}{ }^{-}$ under (a) heating and (b) cooling both at $2{ }^{\circ} \mathrm{C} / \mathrm{min}$ and (c) peak position as a function of temperature during cooling and heating at $2{ }^{\circ} \mathrm{C} / \mathrm{min}$.

In multi-cationic mixtures, as the samples studied here, without a priori knowledge if the composition was close to the eutectic point, we expected a splitting of the $\omega_{1}$ mode due to the presence of different cationic domains. Table 2 shows the frequencies of the symmetric stretching mode of $\mathrm{NO}_{3}{ }^{-}$for pure salts in liquid and solid state. As can be seen in the table, there is a substantial shift in frequency of the vibrational mode that depends on the environment of $\mathrm{NO}_{3}{ }^{-}$. However, no splitting of the $\omega_{1}$ band was observed that could be associated to different cationic domains in the samples.

Table 2. Raman frequencies $\left(\mathrm{cm}^{-1}\right)$ corresponding to the symmetric stretching of $\mathrm{NO}_{3}{ }^{-}$for pure salts in liquid and solid states [31,32]

\begin{tabular}{|c|c|c|c|c|c|c|}
\cline { 2 - 7 } \multicolumn{1}{c|}{} & \multicolumn{7}{c|}{ Salt } \\
\hline Raman mode & $\mathbf{L i N O}_{\mathbf{3}}$ & $\mathbf{N a N O}_{\mathbf{3}}$ & $\mathbf{K N O}_{3}$ & $\mathbf{R b N O}_{3}$ & $\mathbf{C s N O}_{3}$ & $\mathbf{C a}\left(\mathrm{NO}_{3}\right)_{\mathbf{2}}$ \\
\hline$\omega_{1}$ (liquid state) & 1067 & 1053 & 1048 & 1046 & 1043 & \\
\hline$\omega_{1}$ (solid state) & 1086 & 1069 & 1050 & 1056 & 1050 & $1069 *[32]$ \\
\hline
\end{tabular}

The distortion of the band in the spectra of S-Al and S-Rb has been clearly associated to the amorphous fraction of the samples. Therefore, the narrow linewidth of the band in the solid state, for samples S-Al and S-Rb, denotes that the cationic environment is homogeneous. 
The difficulty of samples $Q$ and S-Al to crystallize is evident even at low cooling rates, as can be observed in the Raman spectra recorded under cooling conditions at a rate of $2{ }^{\circ} \mathrm{C} / \mathrm{min}$ (Figure $\mathbf{5 b}$ and Figure $\mathbf{7 b}$ ).

It is clear that the handling of the material before the Raman analyses is crucial for the interpretation of the spectra. As can be observed in Figure 7, for sample Q, from room temperature to $127^{\circ} \mathrm{C}$, the broad linewidth and line-shape of the band remained unaltered as a function of temperature. Similar behavior was observed during the cooling process (from 127 to $-10^{\circ} \mathrm{C}$ ). As was mentioned in the methodology section, the samples were melted prior to the characterization in order to properly place the sample in the equipment. In the case of sample $Q$, it was observed that the kinetic of crystallization of the salt was very slow. This statement is supported by the data from the Raman spectra and XRD data taken right after melting the sample and 1-2 hours later (see Figure $\mathbf{S} 1$ in the supporting information).

Finally, it has been demonstrated that the solid-to-liquid transition in nitrate salts can be detected by Raman spectroscopy by monitoring the linewidth and line-shape of internal vibrational modes. In glass and molten states the bands corresponding to the internal modes of $\mathrm{NO}_{3}{ }^{-}$become an order of magnitude broader than in crystalline state, as was observed in the spectra.

Furthermore, the $3 \omega$ technique and the optical transmission equipment have also been proven to be suitable techniques to detect solid-to-liquid transitions in molten salts. Table 3 summarizes the values for the melting temperature range of the salts using DSC, $3 \omega$ technique, optical transmission and Raman spectroscopy.

Table 3. Melting temperature range of the salts measured by DSC, optical transmission, $3 \omega$ technique and Raman spectroscopy.

\begin{tabular}{|c|c|c|c|}
\hline \multirow{3}{*}{ Techniques } & \multicolumn{3}{|c|}{ Melting temperature range $\left({ }^{\circ} \mathrm{C}\right)$} \\
\hline & \multicolumn{3}{|c|}{ Samples } \\
\hline & $S-A I$ & $S-R b$ & $Q$ \\
\hline DSC & $75-115$ & - & - \\
\hline Optical transmission & $60-96$ & $60-100$ & $60-100$ \\
\hline $3 \omega$ technique & $76-100$ & $60-100$ & $60-100$ \\
\hline Raman spectroscopy & $96-118$ & $60-100$ & - \\
\hline
\end{tabular}




\section{Conclusions}

An important feature of multi-component salts is that the difference in size of the species hinders the crystallization and provides lower melting temperatures. Herein, two novel sixcomponent nitrates 'S-Al' ( $\mathrm{LiNaKCsCaAl} / \mathrm{NO}_{3}$ ) and 'S-Rb' ( $\mathrm{LiNaKRbCsCa} / \mathrm{NO}_{3}$ ) were for the first time prepared and thermally characterized. These molten salts have low melting temperatures of $\approx 60-75^{\circ} \mathrm{C}$ and a thermal stability above $500{ }^{\circ} \mathrm{C}$ under a linear heating program of $10^{\circ} \mathrm{C} / \mathrm{min}$ in $\mathrm{N}_{2}$ atmosphere. A complete study on the thermal properties of the materials was performed to evaluate their possible performance as heat transfer and storage materials. Their specific heat capacity values are close to that of the Halotechnics SS-500 and $\mathrm{NaKCsNO}_{3}$ salts [19] and are slightly below that of the Solar salt [29]. The average thermal conductivity of these salts in the liquid state is slightly smaller than that of the Solar salt $\left(\approx 0.520 \mathrm{~W} \mathrm{~m}^{-1} \mathrm{~K}^{-1}\right)$ [29] and similar or even larger than that of Hitec $\left(\approx 0.350 \mathrm{~W} \mathrm{~m}^{-1} \mathrm{~K}^{-1}\right)$ [30]. A comparative study on the thermal stability of the salts by thermogravimetric analysis showed that samples S-Al and S-Rb are as thermally stable as Halotechnics SS-500 [16] and comparable to Na-K-Li nitrates [1].

The determination of the solid-to-liquid transition of these materials can be complex. The internal structure of multi-component salts can be affected by the cooling rate and/or water presence. These factors may influence the crystallization or amorphization of the material. To deepen into the thermal behavior of the materials, complementary and alternative techniques were used. The melting temperature of the salts was estimated by three alternative techniques: optical transmission, the $3 \omega$ technique and Raman spectroscopy. The monitoring of properties such as variation in transparency, thermal conductivity and internal vibrations of the salts as a function of temperature was demonstrated to be useful indicators of the solid-toliquid phase change.

The Raman spectra analysis revealed relevant information about the internal structure of the salts. The monitoring of the symmetric stretching mode of $\mathrm{NO}_{3}{ }^{-}$as a function of temperature provided information about the distribution of the cationic environment, the ordering of the solid below melting point and the onset melting temperature.

The difficulty in the ordering of these multi-cationic nitrate mixtures during cooling was also demonstrated, confirming previous findings in the literature $[26,27]$ stating that a variable cationic environment (cations with different sizes) favors glass formation during fast cooling. $X-$ ray diffraction analyses as a function of time and humidity (see supporting information), showed that water acts as a catalyst for crystallization, providing mobility to the ions within the material. Furthermore, the addition of $\mathrm{RbNO}_{3}$ and $\mathrm{Al}\left(\mathrm{NO}_{3}\right)_{3}$ to the original 5-component recipe of Halotechnics SS-500 (Q) favors the crystallization of the material, as displayed in the $\mathrm{X}$-ray diffractograms as a function of time.

Our results suggest that these two new nitrate-based salts could be potential candidates for heat transfer and storage applications in CSP technology due to their low melting temperature, high thermal stability, good thermal conductivity and specific heat capacity, although further research is needed. Furthermore, three alternative techniques to DSC have been presented and validated to detect solid-to-liquid phase transitions. These unprecedented techniques for phase change detection widen the number of characterization methods in the field of thermal solar energy.

There is little known about multi-component salts. Their amorphous nature is not necessarily an inconvenient for their application in CSP systems. If the initial state of the material is crystalline, it can be stored above its melting temperature and used as thermal storage material or heat transfer fluid for high temperature applications. All the results gathered show the complex behavior of this sort of materials. However, the complexity is nothing but gaps in the field. Future studies on the internal structure and amorphous behavior of multi- 
component salts are expected to fill those gaps. This knowledge will be crucial to the application of these materials in the thermal-solar field, among others.

\section{Acknowledgments}

The Catalan Institute of Nanoscience and Nanotechnology (ICN2) acknowledges support from the Severo Ochoa Program (MINECO, Grant SEV-2017-0706) and funding from the CERCA Programme/Generalitat de Catalunya. Funding from the Spanish Ministry MINECO/FEDER: FIS2015-70862-P PHENTOM and MAT2015-68394-R NaCarFLOW are also acknowledged. M.-C. $L$ acknowledges support from the Ministry of Science and Technology in Taiwan, MOST 1042221-E-009-147-MY3. We thank Dr. Jessica Padilla for the assistance provided with XRD analysis. MRRL would like to thank Dr. Carlos Gracia for the valuable discussions. We would also like to thank Andrew Hudson and Dr. Guy L. Whitworth for the assistance provided with English writing in the manuscript.

\section{References}

[1] K. Vignarooban, X. Xu, A. Arvay, K. Hsu, A.M. Kannan, Heat transfer fluids for concentrating solar power systems - A review, Appl. Energy. 146 (2015) 383-396. doi:10.1016/j.apenergy.2015.01.125.

[2] H.L. Zhang, J. Baeyens, J. Degrève, G. Cacères, Concentrated solar power plants: Review and design methodology, Renew. Sustain. Energy Rev. 22 (2013) 466-481. doi:10.1016/j.rser.2013.01.032.

[3] M. Liu, N.H. Steven Tay, S. Bell, M. Belusko, R. Jacob, G. Will, W. Saman, F. Bruno, Review on concentrating solar power plants and new developments in high temperature thermal energy storage technologies, Renew. Sustain. Energy Rev. 53 (2016) 1411-1432. doi:10.1016/j.rser.2015.09.026.

[4] L. Miró, J. Gasia, L.F. Cabeza, Thermal energy storage (TES) for industrial waste heat (IWH) recovery: A review, Appl. Energy. 179 (2016) 284-301. doi:10.1016/j.apenergy.2016.06.147.

[5] J. Gasia, L. Miró, L.F. Cabeza, Review on system and materials requirements for high temperature thermal energy storage. Part 1: General requirements, Renew. Sustain. Energy Rev. 75 (2017) 1320-1338. doi:10.1016/j.rser.2016.11.119.

[6] G. Alva, L. Liu, X. Huang, G. Fang, Thermal energy storage materials and systems for solar energy applications, Renew. Sustain. Energy Rev. 68 (2017) 693-706. doi:10.1016/j.rser.2016.10.021.

[7] E. Zarza, Medium Temperature Solar Concentrators (Parabolic-Troughs Collectors), in: Sol. Energy Convers. Photoenergy Syst., 2005.

[8] H. Müller-Steinhagen, F. Trieb, Concentrating Solar Power: A review of the technology, Ingenia. 18 (2004) 43-50.

[9] C. Villada, A. Bonk, T. Bauer, F. Bolívar, High-temperature stability of nitrate/nitrite molten salt mixtures under different atmospheres, Appl. Energy. 226 (2018) 107-115. doi:10.1016/j.apenergy.2018.05.101. 
[10] T. Bauer, N. Breidenbach, N. Pfleger, D. Laing, M. Eck, Overview of molten salt storage systems and material development for solar thermal power plants, Proc. $2012 \mathrm{Natl}$. Sol. Conf. (SOLAR 2012) Denver. (2012).

[11] I. Sarbu, C. Sebarchievici, A comprehensive review of thermal energy storage, Sustain. 10 (2018). doi:10.3390/su10010191.

[12] U. Pelay, L. Luo, Y. Fan, D. Stitou, M. Rood, Thermal energy storage systems for concentrated solar power plants, Renew. Sustain. Energy Rev. 79 (2017) 82-100. doi:10.1016/j.rser.2017.03.139.

[13] E. González-Roubaud, D. Pérez-Osorio, C. Prieto, Review of commercial thermal energy storage in concentrated solar power plants: Steam vs. molten salts, Renew. Sustain. Energy Rev. 80 (2017) 133-148. doi:10.1016/j.rser.2017.05.084.

[14] R.I. Olivares, W. Edwards, LiNO3-NaNO3-KNO3 salt for thermal energy storage: Thermal stability evaluation in different atmospheres, Thermochim. Acta. 560 (2013) 34-42. doi:10.1016/j.tca.2013.02.029.

[15] T. Wang, D. Mantha, R.G. Reddy, Novel low melting point quaternary eutectic system for solar thermal energy storage, Appl. Energy. 102 (2013) 1422-1429. doi:10.1016/j.apenergy.2012.09.001.

[16] J.W. Raade, D. Padowitz, Development of Molten Salt Heat Transfer Fluid With Low Melting Point and High Thermal Stability, J. Sol. Energy Eng. 133 (2011) 31013. doi:10.1115/1.4004243.

[17] N. Ren, Y. Wu, C. Ma, L. Sang, Preparation and thermal properties of quaternary mixed nitrate with low melting point, Sol. Energy Mater. Sol. Cells. 127 (2014) 6-13. doi:10.1016/j.solmat.2014.03.056.

[18] A.G. Fernández, S. Ushak, H. Galleguillos, F.J. Pérez, Development of new molten salts with LiNO3 and $\mathrm{Ca}(\mathrm{NO} 3) 2$ for energy storage in CSP plants, Appl. Energy. 119 (2014) 131-140. doi:10.1016/j.apenergy.2013.12.061.

[19] P. Zhang, J. Cheng, Y. Jin, X. An, Evaluation of thermal physical properties of molten nitrate salts with low melting temperature, Sol. Energy Mater. Sol. Cells. 176 (2018) 3641. doi:10.1016/j.solmat.2017.11.011.

[20] R. Serrano-López, J. Fradera, S. Cuesta-López, Molten salts database for energy applications, Chem. Eng. Process. Process Intensif. 73 (2013) 87-102. doi:10.1016/j.cep.2013.07.008.

[21] K. Wang, B. Xu, P. Lucas, S.M. Jeter, Experimental Investigation to the Properties of Eutectic Salts by $\mathrm{NaCl}-\mathrm{KCl}-\mathrm{ZnCl} 2$ for Application as High Temperature Heat Transfer Fluids, Proc. ASME 2014 8th Int. Conf. Energy Sustain. (2014) 1-6.

[22] L. Sang, M. Cai, N. Ren, Y. Wu, C. Burda, C. Ma, Improving the thermal properties of ternary carbonates for concentrating solar power through simple chemical modifications by adding sodium hydroxide and nitrate, Sol. Energy Mater. Sol. Cells. 124 (2014) 61-66. doi:10.1016/j.solmat.2014.01.025.

[23] Q. Peng, J. Ding, X. Wei, J. Yang, X. Yang, The preparation and properties of multicomponent molten salts, Appl. Energy. $87 \quad$ (2010) 2812-2817. doi:10.1016/j.apenergy.2009.06.022. 
[24] C. Martin, T. Bauer, H. Müller-Steinhagen, An experimental study of a non-eutectic mixture of KNO3 and $\mathrm{NaNO} 3$ with a melting range for thermal energy storage, Appl. Therm. Eng. 56 (2013) 159-166. doi:10.1016/j.applthermaleng.2013.03.008.

[25] R.I. Olivares, C. Chen, S. Wright, The Thermal Stability of Molten Lithium-SodiumPotassium Carbonate and the Influence of Additives on the Melting Point, J. Sol. Energy Eng. 134 (2012) 41002. doi:10.1115/1.4006895.

[26] L.G. van Uitert, W.H. Grodkiewicz, Nitrate glasses, Mater. Res. Bull. 6 (1971) 283-291. doi:10.1016/0025-5408(71)90042-0.

[27] T. Furukawa, S.A. Brawer, W.B. White, Raman spectroscopic study of nitrate glasses, J. Chem. Phys. 69 (1978) 2639. doi:10.1063/1.436912.

[28] M.R. Rodríguez-Laguna, A.. Castro-Alvarez, M. Sledzinska, J. Maire, F.. Costanzo, B.. Ensing, M.. Pruneda, P. Ordejón, C.M. Sotomayor Torres, P. Gómez-Romero, E. ChávezÁngel, Mechanisms behind the enhancement of thermal properties of graphene nanofluids, Nanoscale. 10 (2018) 15402-15409. doi:10.1039/C8NR02762E.

[29] N. Ren, Y.T. Wu, C.F. Ma, L.X. Sang, Preparation and thermal properties of quaternary mixed nitrate with low melting point, Sol. Energy Mater. Sol. Cells. 127 (2014) 6-13. doi:10.1016/j.solmat.2014.03.056.

[30] L.L.C. Coastal Chemical Co., HITEC ${ }^{\circledR}$ Heat Transfer Salt. Technical Data Guide, (2009).

[31] G.J. Janz, D.W. James, Raman Spectra and Ionic Interactions in Molten Nitrates, J. Chem. Phys. 35 (1961) 739-745. doi:10.1063/1.1731994.

[32] M.H. Brooker, Raman and i.r. spectra of zinc, cadmium and calcium nitrate: A study of the low temperature phase transitions in calcium nitrate, Spectrochim. Acta Part A Mol. Spectrosc. 32 (1976) 369-377. doi:10.1016/0584-8539(76)80090-6. 